\title{
Higher Alcohol Synthesis Over Rh Catalysts: Conditioning of Rh/N-CNTs by Co and Mn Entrapped in the Support
}

\author{
Zailai Xie $^{1,2} \cdot$ Benjamin Frank $^{1,3} \cdot$ Xing Huang $^{1} \cdot$ Robert Schlögl $^{1}$. \\ Annette Trunschke ${ }^{1}$
}

Received: 4 July 2016 / Accepted: 26 September 2016 / Published online: 13 October 2016

(C) The Author(s) 2016. This article is published with open access at Springerlink.com

\begin{abstract}
Rh}$ nanoparticles supported on commercial non-purified N-doped CNTs (NCNTs) containing residual CNT growth catalyst have been studied in hydrogenation of $\mathrm{CO}$ to higher alcohols. It has been found that $\mathrm{Co}$ and Mn residues in NCNTs are not inert, but change the catalyst under reaction conditions and efficiently promote the catalyst resulting in both increasing activity and selectivity to $\mathrm{C}_{2+}$ alcohols with time on stream.
\end{abstract}

Zailai Xie and Benjamin Frank have contributed equally to this work.

Electronic Supplementary Material The online version of this article (doi:10.1007/s10562-016-1875-6) contains supplementary material, which is available to authorized users.

Annette Trunschke

trunschke@fhi-berlin.mpg.de

1 Department of Inorganic Chemistry, Fritz-Haber-Institut der Max-Planck-Gesellschaft, Faradayweg 4-6, 14195 Berlin, Germany

2 Present address: College of Chemsitry, Fuzhou University, Qishan Campus, 2 Xueyuan Road, 350116 Fuzhou, People's Republic of China

3 Present address: BasCat - UniCat BASF JointLab, Technische Universität Berlin, Sekr. EW K 01, Hardenbergstr. 36, 10623 Berlin, Germany
Graphical Abstract

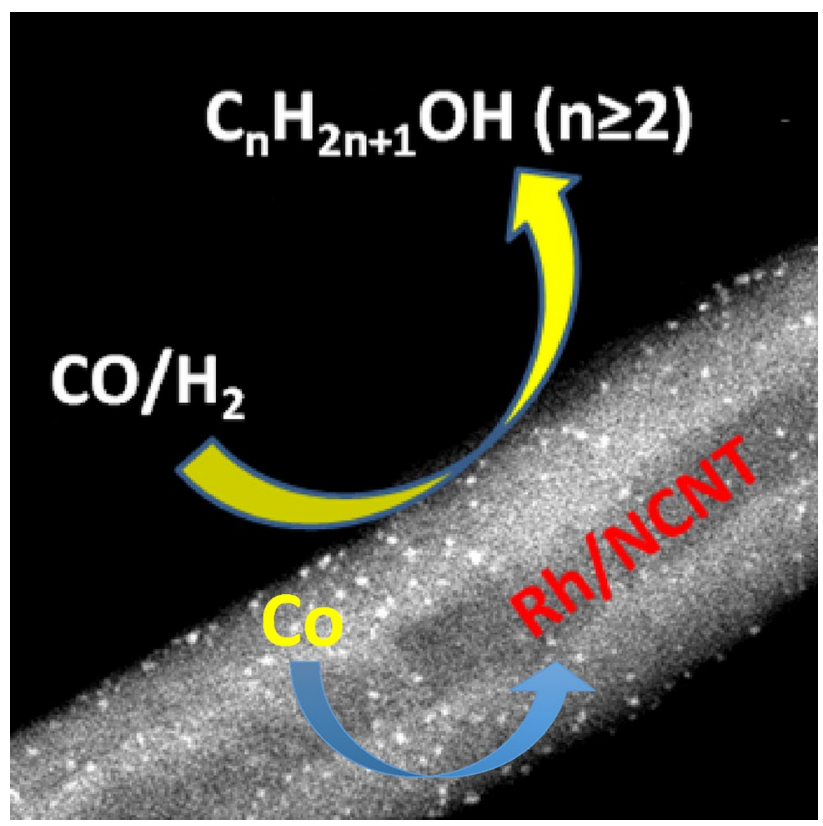

Keywords Rhodium - Cobalt · Manganese · CNT growth catalyst · Higher alcohol synthesis · Carbon nanotubes $\cdot$ Nitrogen doping $\cdot$ Nanoparticles

\section{Introduction}

Higher alcohols $\left(\mathrm{C}_{2+}\right)$ are industrial key intermediates and low-emission fuels usually produced in multi-step processes $[1,2]$. A direct route from syngas is highly desirable to cope with clean energy demands [1-5]. However, the Fischer-Tropsch (FT) approach so far fails in obtaining 
higher alcohols with a sufficient selectivity at a high level of CO conversion $[6,7]$. Considerable effort has been devoted to improving the catalyst performance by optimizing the active phases, adding promoters, and varying catalyst supports $[1,2,4,6,8-10]$. Model catalysts based on Rh exhibit a unique selectivity to oxygenates due to moderate ability for $\mathrm{CO}$ dissociation $[6,8,10-13]$. Here, a variety of transition metals were identified as efficient dopants, e.g., Mn, Fe, Co, Mo, or Zr [8, 14-16].

Besides the active phase, the support plays a key role in determining the alcohol productivity, e.g., by metal-support interaction, which governs the dispersion and stability of metal nanoparticles [17]. Several studies indicated that CNTs are more efficient supports for higher alcohol synthesis $[8,17-20]$ than conventional metal oxides such as $\mathrm{Al}_{2} \mathrm{O}_{3}$ [21], and $\mathrm{SiO}_{2}[5,9,22]$. On the other hand, $\mathrm{N}$-doping of nanocarbons is known to efficiently increase the dispersion of noble metal nanoparticles [17, 23-25].

Here, we investigate the application of commercial $\mathrm{N}$-doped CNTs as support for Rh-based catalysts in higher alcohol synthesis. It turned out that residual metal oxides in NCNTs have an impact on the catalytic performance of Rh by changing the catalyst under reaction conditions of $\mathrm{CO}$ hydrogenation.

\section{Experimental}

\subsection{Catalyst Synthesis}

We compared (1) CVD-grown commercial NCNTs (NCNT1) [26], (2) pre-oxidized high-purity CNTs (OCNT), and (3) $\mathrm{N}$-doped CNT, which were produced by $\mathrm{NH}_{3}$ treatment of OCNT (NCNT-2) [27].

Unpurified CVD-grown NCNTs (NCNT-1; support ID 12836) have been received from Bayer Material Science [26].

Purified CNTs (Baytubes C150 $\mathrm{HP}^{\circledR}$, carbon content $>99 \mathrm{wt} \%$, bulk density $140-230 \mathrm{~kg} \mathrm{~m}^{-3}$ ) with $13 \mathrm{~nm}$ outer diameter and $4 \mathrm{~nm}$ inner diameter in average were obtained from Bayer Material Science. $20 \mathrm{~g}$ CNTs were treated in $1 \mathrm{~L}$ concentrated nitric acid (Carl Roth, $65 \mathrm{wt} \%$, p.a.) under reflux for a period of $4 \mathrm{~h}$. After cooling down to ambient temperature, the oxidized sample was thoroughly washed and filtrated with Millipore water until neutral $\mathrm{pH}$. Finally, the resulting carbon was dried at $110^{\circ} \mathrm{C}$ in static air for 3 days (OCNT; support ID 16603).

Nitrogen incorporation into purified oxidized CNTs was performed by treatment of $4 \mathrm{~g}$ OCNT in $50 \% \mathrm{NH}_{3}$ in $\mathrm{Ar}$ at $150 \mathrm{~mL}_{\mathrm{n}} \mathrm{min}^{-1}$ in a rotating tubular quartz reactor $(40 \mathrm{~mm}$ inner diameter and $740 \mathrm{~mm}$ in length). The sample was heated at $5{ }^{\circ} \mathrm{C} \mathrm{min}^{-1}$ to $500^{\circ} \mathrm{C}$. The target temperature was maintained for $6 \mathrm{~h}$. Afterwards the sample was cooled down to ambient temperature in the $\mathrm{NH}_{3} / \mathrm{Ar}$ mixture (NCNT-2; support ID 17790).

$\mathrm{Rh} / \mathrm{N}(\mathrm{O}) \mathrm{CNTs}$ catalysts were prepared by wet impregnation. $450 \mathrm{mg} \mathrm{Rh}\left(\mathrm{NO}_{3}\right)_{3}(10 \% \mathrm{Rh}$, Sigma) was dissolved in $8 \mathrm{~mL}$ de-ionized water. The solution $(\mathrm{pH} 3$ ) was then added to $1.5 \mathrm{~g}$ functionalized CNTs. Ultra-sonication was carried out for $1 \mathrm{~min}$ followed by evacuation at room temperature. The sample was reduced at $350^{\circ} \mathrm{C}$ for $2 \mathrm{~h}$ in $20 \% \mathrm{H}_{2}$ in $\mathrm{Ar}$ at a total flow of $100 \mathrm{~mL} \mathrm{~min}{ }^{-1}$ resulting in the catalysts Rh/NCNT-1 (catalyst ID 15318), Rh/NCNT-2 (catalyst ID 18232), and Rh/OCNT (catalyst ID 17863), respectively.

$\mathrm{RhCo} / \mathrm{OCNT}$ (catalyst ID 16999) and RhMn/OCNT (catalyst ID 16915) reference catalysts were prepared by wet impregnation using $\mathrm{Rh}\left(\mathrm{NO}_{3}\right)_{3}, \mathrm{Co}\left(\mathrm{NO}_{3}\right)_{2} \cdot 6 \mathrm{H}_{2} \mathrm{O}$, and $\mathrm{Mn}\left(\mathrm{NO}_{3}\right)_{2} \cdot 4 \mathrm{H}_{2} \mathrm{O}$ as precursors and OCNT as support. The impregnation was performed in two steps starting with $\mathrm{Rh}$, followed by reduction at $350^{\circ} \mathrm{C}$ for $2 \mathrm{~h}$ in $20 \% \mathrm{H}_{2} / \mathrm{Ar}$ gas mixture and subsequent impregnation with Co or Mn salts. Finally, the catalysts were reduced at second time at $350{ }^{\circ} \mathrm{C}$ for $2 \mathrm{~h}$ in $20 \% \mathrm{H}_{2} /$ Ar gas mixture.

\subsection{Characterization of Supports and Catalysts}

Scanning electron microscopy (SEM) images were obtained using a Hitachi S-4800 FEG microscope $(1.5 \mathrm{kV})$ equipped with an EDAX Genesis EDX detector (15 kV). Transmission electron microscopy (TEM) bright field images were taken using a Philips CM200 microscope equipped with a $\mathrm{LaB}_{6}$ cathode at an acceleration voltage of $200 \mathrm{kV}$. The nanostructure of supported metal particles was examined using a FEI aberration-corrected Titan 80-300 TEM microscope operated at $300 \mathrm{kV}$. For TEM analysis the samples were deposited onto holey carbon coated $\mathrm{Cu}$ grids without using a solvent. Particle size distributions have been obtained by analyzing 100 particles for Rh/NCNT-1, 200 particles for Rh/OCNT, and 125 particles for Rh/NCNT-2, respectively.

$\mathrm{N}_{2}$ physisorption was performed at $-196^{\circ} \mathrm{C}$ in the range $p / p_{0}=0.05-0.3$ after drying the sample in vacuum at $120^{\circ} \mathrm{C}$ for $6 \mathrm{~h}$ applying a volumetric $\mathrm{N}_{2}$ physisorption apparatus (Autosorb-6-B, Quantachrome).

The XRD measurements were performed on a Bruker AXS D8 ADVANCE II diffractometer equipped with a nickel filter and a LYNXEYE position sensitive detector $\left(\mathrm{Cu} \mathrm{K}_{\alpha 1+2}\right.$ radiation) in Bragg-Brentano geometry (fixed divergence slit).

Temperature-programmed reduction (TPR) of the catalysts was performed in a quartz fixed-bed tubular reactor (TPDRO-1100, CE Instruments) in 5.04\% $\mathrm{H}_{2} / \mathrm{Ar}$ $\left(80 \mathrm{~mL} \mathrm{~min}^{-1}\right.$ applying a heating rate of $5 \mathrm{~K} \mathrm{~min}^{-1}$ ). The $\mathrm{H}_{2}$ consumption was monitored using a thermal conductivity detector (TCD). The TCD detector was calibrated by reducing a known amount of $\mathrm{CuO}$.

Analysis of the nitrogen content ( $\mathrm{CHN}$ analysis) was done using a Thermo FlashEA 1112 NC Analyzer. The 
metal content in the catalysts was analyzed by X-ray fluorescence spectroscopy (XRF) using a Bruker S4 Pioneer $\mathrm{X}$-ray spectrometer.

Zeta potential measurements were performed using a Malvern Zetasizer. Approximately $5 \mathrm{mg}$ of CNFs were dispersed in $100 \mathrm{~mL}$ deionized water and sonicated for $10 \mathrm{~min}$. Thereafter, the suspensions were kept at $25^{\circ} \mathrm{C}$ and the $\mathrm{pH}$ was adjusted manually using $0.1 \mathrm{M}$ sodium hydroxide and hydrogen chloride, respectively, and the zeta potential was measured.

X-ray photoelectron spectroscopy (XPS) measurements were performed at ambient temperature under UHV conditions (base pressure $<3 \times 10^{-10} \mathrm{~m}$ bar) employing nonmonochromated $\mathrm{Al} \mathrm{K}_{\alpha}$ radiation source $(1486.6 \mathrm{eV})$. Spectra were acquired using a hemispherical analyzer (Phoibos 150, SPECS) operated in fixed analyzer transmission mode at a pass energy of $20 \mathrm{eV}$.

\subsection{CO Hydrogenation}

CO hydrogenation was carried out in a high-pressure set up. $800 \mathrm{mg}$ of catalyst (powder, $200 \sim 400 \mu \mathrm{m}$ ) was loaded into a tubular stainless steel fixed bed reactor. The standard reaction conditions were: $p=100$ bar, $\mathrm{H}_{2} / \mathrm{CO}=1, T=350^{\circ} \mathrm{C}$, flow rate $=10 \mathrm{~mL} \mathrm{~min}^{-1}$. The setup and the method of product analysis have been described elsewhere [28].

\section{Results and Discussion}

\subsection{Characterization of the Supports}

All supports have outer and inner diameters of 10-15 and 3-5 nm, respectively (see for example a representative SEM image of NCNT-1 in Fig. S1). Elemental composition and specific surface area of supports are listed in Table 1.

Chemical vapor deposition (CVD) over mixed metal catalysts (Mg, $\mathrm{Al}, \mathrm{Mn}, \mathrm{Co}$ ) was used to produce NCNTs on $\mathrm{kg}$ scale [26]. During this process, finely dispersed metal

Table 1 Elemental composition (wt\%) and specific surface area $\left(\mathrm{m}^{2} \mathrm{~g}^{-1}\right)$ of supports and catalysts

\begin{tabular}{lllllllll}
\hline Sample & $\mathrm{N}^{\mathrm{a}}$ & $\mathrm{Rh}^{\mathrm{b}}$ & \multicolumn{3}{c}{ Metal impurities } & \multicolumn{3}{c}{$S_{\text {BET }}$} \\
\cline { 5 - 8 } & & & & $\mathrm{Mg}$ & $\mathrm{Al}$ & $\mathrm{Mn}$ & $\mathrm{Co}$ & \\
\hline NCNT-1 & 4.6 & 0 & 1.4 & 1.4 & 1.5 & 1.5 & 196 \\
NCNT-2 & 1.2 & 0 & - & - & - & - & 324 \\
OCNT & 0 & 0 & - & - & - & - & 338 \\
Rh/NCNT-1 & 4.2 & 2.5 & 1.1 & 1.2 & 1.6 & 1.8 & 175 \\
Rh/NCNT-2 & 0.7 & 2.6 & - & - & - & - & 316 \\
Rh/OCNT & 0 & 2.6 & - & - & - & - & 234
\end{tabular}

${ }^{\mathrm{a}} \mathrm{CHN}$ analysis

${ }^{\mathrm{b}}$ Analysed by X-ray fluorescence (oxide) nanoparticles remain in the raw product as impurities. Scanning electron microscopy (SEM) and transmission electron microscopy (TEM) images of NCNT-1 show many metal oxide particles being encapsulated by a thin carbonaceous layer (Supplementary material, Figure S1, representative SEM (top) and TEM (bottom) images of pristine NCNT-1). The co-existence of $\mathrm{Mg}, \mathrm{Al}, \mathrm{Mn}$, and Co impurities in NCNT-1 was confirmed by X-ray fluorescence (Table 1). Although a substantial purification of $\mathrm{N}$-free CNTs is feasible and typically achieved by refluxing in concentrated $\mathrm{HNO}_{3}$, this approach fails for NCNTs due to the severe loss of surface $\mathrm{N}$ functional groups.

To disentangle the impact of nitrogen and metal doping, NCNTs derived from high-purity pre-oxidized CNTs (OCNT) have been included into the investigation. OCNT and NCNT-2 are free of metal impurities (Table 1).

The assembly of distinct nitrogen species at the surface of NCNT-1 and NCNT-2 was compared by X-ray photoelectron spectroscopy (Figure S2). Pyridinic nitrogen provides the lowest binding energy (BE) of $398.3 \mathrm{eV}(\mathrm{N} 1)$. A peak at $399.2 \mathrm{eV}(\mathrm{N} 2)$ is related to $\mathrm{NH}$ bonds in amides and amines. A feature at $400.1 \mathrm{eV}(\mathrm{N} 3)$ indicates the presence of pyrrolic $\mathrm{N}$, whereas the $\mathrm{BE}$ of $401.1 \mathrm{eV}(\mathrm{N} 4)$ is typically referred to quaternary $\mathrm{N}$ species [29]. A peak at $402.1 \mathrm{eV}$ is related to $\mathrm{N}-\mathrm{O}$ bonds in pyridine-oxide or nitro groups (N5) [30]. Evidently, the surface properties of NCNT-1 and NCNT-2 differ in type (Figure S2) and amount (Table 1) of $\mathrm{N}$-functionalization. Overall nitrogen content and relative abundance of pyridinic nitrogen are higher in NCNT-1.

\subsection{Characterization of Rh Nanoparticles}

The specific surface areas $S_{\mathrm{BET}}$ of the supports decrease upon Rh loading. However, fine dispersion of 2.5-2.6 wt $\%$ $\mathrm{Rh}$ is still possible (Fig. 1). The co-existence of $\mathrm{Mg}, \mathrm{Al}, \mathrm{Mn}$, and Co impurities was also proven in Rh/NCNT-1 (Table 1). SEM (Fig. 1a, c, e), TEM, (Fig. 1b, d, f) and XRD analyses (Figure S3) confirm the dispersion of $\mathrm{Rh}$, the entangled morphology of the (N)CNT samples, and the absence of large agglomerates of residual catalyst impurities in the supports and the reduced catalysts.

For Rh/NCNT-1 high-angle annular dark-field (HAADF) scanning TEM (STEM) reveals highly dispersed and homogeneously distributed $\mathrm{Rh}$ particles with a mean particle size of $1.4 \mathrm{~nm}$ (inset in Fig. 1a, b) after reduction in hydrogen at $350^{\circ} \mathrm{C}$. The high dispersion can be caused by the abundance of $\mathrm{N}$-functionalities serving as anchoring sites on the surface of NCNT-1. A corresponding high-resolution TEM (HRTEM) image (Fig. 2a) shows lattice fringes with $d$-spacing of $0.22 \mathrm{~nm}$, corresponding to the (111) planes of facecentered cubic $(f c c)$ metallic Rh.

In the case of Rh/OCNT, HAADF-STEM shows larger Rh nanoparticles $(2.7 \mathrm{~nm})$ indicating a less ideal metal-support 
Fig. 1 SEM (a, c, e) and HAADF-STEM $(\mathbf{b}, \mathbf{d}, \mathbf{f})$ images, as well as particle size distribution (insets) of freshly reduced $\mathrm{Rh} / \mathrm{NCNT}-1$ based on 100 particles (a, b), Rh/OCNT based on 200 particles $(\mathbf{c}, \mathbf{d})$ and $\mathrm{Rh} / \mathrm{NCNT}-2$ based on 125 particles $(\mathbf{e}, \mathbf{f})$
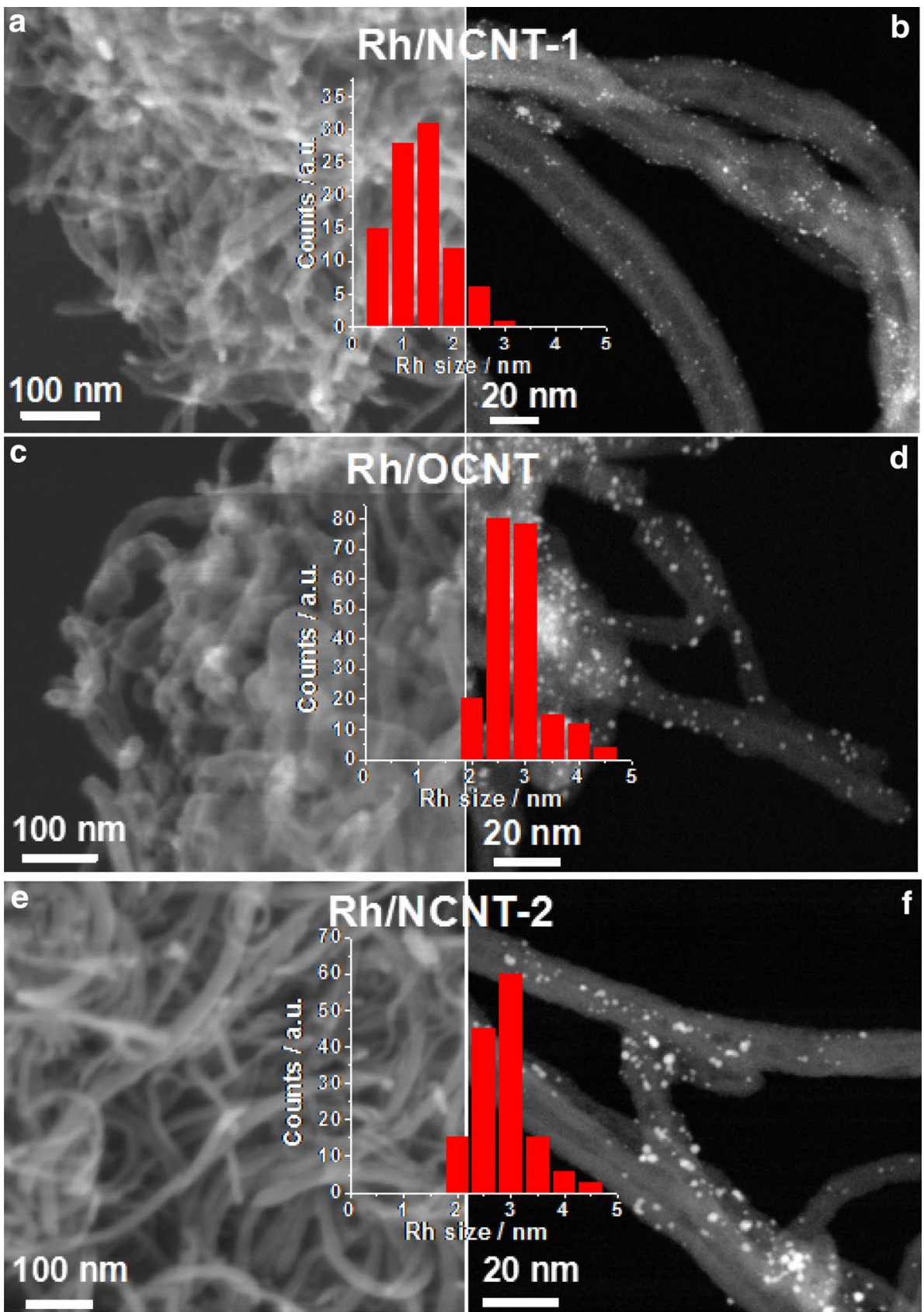

interaction, however, with a rather narrow particle size distribution (inset in Fig. 1c, d). The HRTEM analysis of a selected Rh particle in $\mathrm{Rh} / \mathrm{OCNT}$ exhibits lattice fringes of $f c c \mathrm{Rh}$ (200) with a $d$-spacing of $0.19 \mathrm{~nm}$ (Fig. 2b).

The mean Rh particle size in Rh/NCNT-2 corresponds to $2.6 \mathrm{~nm}$ (inset in Fig. 1f, g).

Considering the abundance of acidic oxygen functionalities generated by $\mathrm{HNO}_{3}$ oxidation of the CNTs, the trend in mean particle sizes can be correlated with the type and amount of surface functional groups (Table 1), which result in the isoelectric point of the different $(\mathrm{N}) \mathrm{CNT}$ surfaces of 4.7, 3.8, and 2.8 for NCNT-1, NCNT-2, and OCNT, respectively (Figure S4).
For instance, the smaller Rh nanoparticles on NCNT-1 as compared to NCNT-2 might indicate an improved Rh-N interaction with pyridinic $\mathrm{N}$ species, leading to a better dispersion in the reduced catalyst. The similar particle size distribution in $\mathrm{Rh} / \mathrm{OCNT}$ and $\mathrm{Rh} / \mathrm{NCNT}-2$ indicates that the relevant pyridinic N-content in NCNT-2 is apparently too low (as revealed by the larger Rh particles present in NCNT-2 compared to NCNT-1).

The temperature-programmed reduction (TPR) of the catalysts provides similar profiles of $\mathrm{H}_{2}$ consumption (Figure S5) with a sharp peak at $166 \pm 2{ }^{\circ} \mathrm{C}$. The absolute consumption of $\mathrm{H}_{2}$ at $40-330^{\circ} \mathrm{C}$ corresponds to $0.40,0.39$, and $0.42 \mathrm{mmol} \mathrm{g}^{-1}$ for Rh/NCNT-1, Rh/NCNT-2, and Rh/ 

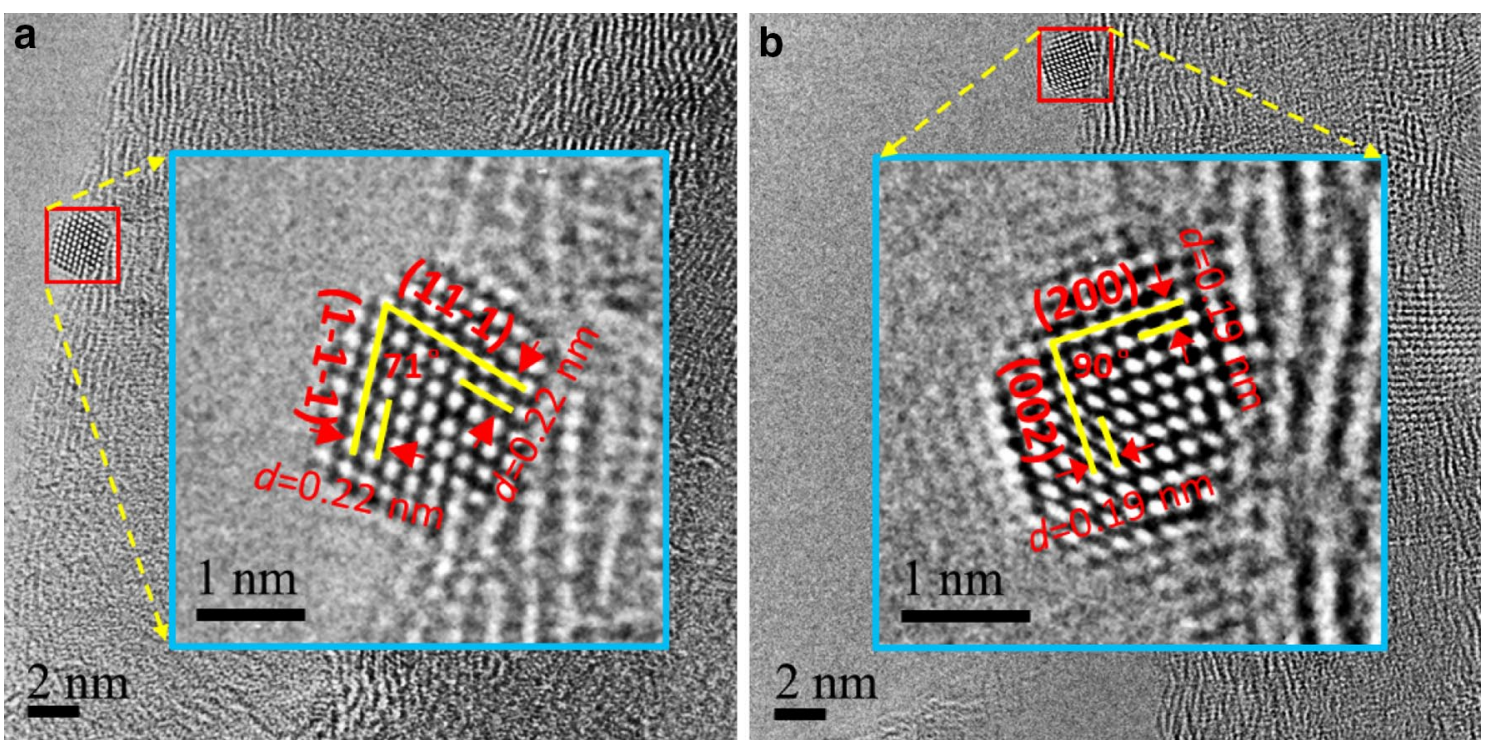

Fig. 2 HRTEM images of (a) Rh/NCNT-1 and (b) Rh/OCNT

OCNT, respectively, in agreement with the theoretical $\mathrm{H}_{2}$ consumption of $0.37 \mathrm{mmol} \mathrm{g}^{-1}$. Accordingly, Rh species in all catalysts are completely reduced in $\mathrm{H}_{2}$ at $350^{\circ} \mathrm{C}$. The additional $\mathrm{H}_{2}$ consumption at $\mathrm{T}>350^{\circ} \mathrm{C}$ could be referred to the reduction of $\mathrm{N}$ and $\mathrm{O}$ functional groups on the carbonaceous support, the hydrogenation of the CNTs, as well as partial reduction of $\mathrm{Co}$ and $\mathrm{Mn}$ species on $\mathrm{Rh} / \mathrm{NCNT}-1$, catalyzed by Rh [31].

\subsection{Catalytic Properties}

The catalysts were tested in $\mathrm{H}_{2} / \mathrm{CO}=1$ at $350^{\circ} \mathrm{C}$ and 100 bar for a period of $72 \mathrm{~h}$ (Fig. 3).

Among the Rh-free support materials only NCNT-1 shows a significant $\mathrm{CO}$ conversion of $7.9 \%$, which is
Table 2 Catalytic performances after a reaction time of $72 \mathrm{~h}$

\begin{tabular}{|c|c|c|c|c|c|c|c|}
\hline \multirow[t]{2}{*}{ Catalyst } & \multirow{2}{*}{$\begin{array}{l}X(\mathrm{CO}) \\
(\%)\end{array}$} & \multicolumn{6}{|c|}{$S(\mathrm{at} \% \mathrm{C})^{\mathrm{a}}$} \\
\hline & & $\mathrm{MeOH}$ & $\begin{array}{l}\mathrm{C}_{2+} \\
\text { alc. }\end{array}$ & $\begin{array}{l}\mathrm{C}_{2+} \\
\text { oxy. }\end{array}$ & $\mathrm{CH}_{4}$ & $\begin{array}{l}\mathrm{C}_{2+} \\
\mathrm{HC}\end{array}$ & $\mathrm{CO}_{2}$ \\
\hline NCNT-1 & 7.9 & - & - & - & 19.6 & 11.4 & 75.6 \\
\hline NCNT-2 & 3 & - & - & - & 60 & 5 & 35 \\
\hline OCNT & 3.5 & - & - & - & 62 & 6 & 36 \\
\hline $\mathrm{Rh} / \mathrm{NCNT}-1$ & 48.9 & 1 & 9.5 & 3.6 & 33.2 & 21.8 & 30.9 \\
\hline $\mathrm{Rh} / \mathrm{NCNT}-2$ & 23 & 2.3 & 8.1 & 6.6 & 15.8 & 21.1 & 46 \\
\hline $\mathrm{Rh} / \mathrm{OCNT}$ & 24.8 & 2.4 & 12.5 & 6.4 & 15.6 & 21.5 & 41.3 \\
\hline $\mathrm{RhMn} / \mathrm{OCNT}$ & 29.3 & 2.1 & 14.8 & 8.2 & 14.5 & 22.2 & 38.2 \\
\hline $\mathrm{RhCo} / \mathrm{OCNT}$ & 53 & 0.8 & 6.2 & 6.2 & 18 & 36.8 & 32 \\
\hline
\end{tabular}

a alc. alcohols, oxy. oxygenates, $H C$ hydrocarbons
Fig. 3 Conversion of $\mathrm{CO}(\mathbf{a})$, and yield of higher alcohols (b) as a function of time on stream, $\mathrm{H}_{2} / \mathrm{CO}=1.0,100$ bar, $350^{\circ} \mathrm{C}$
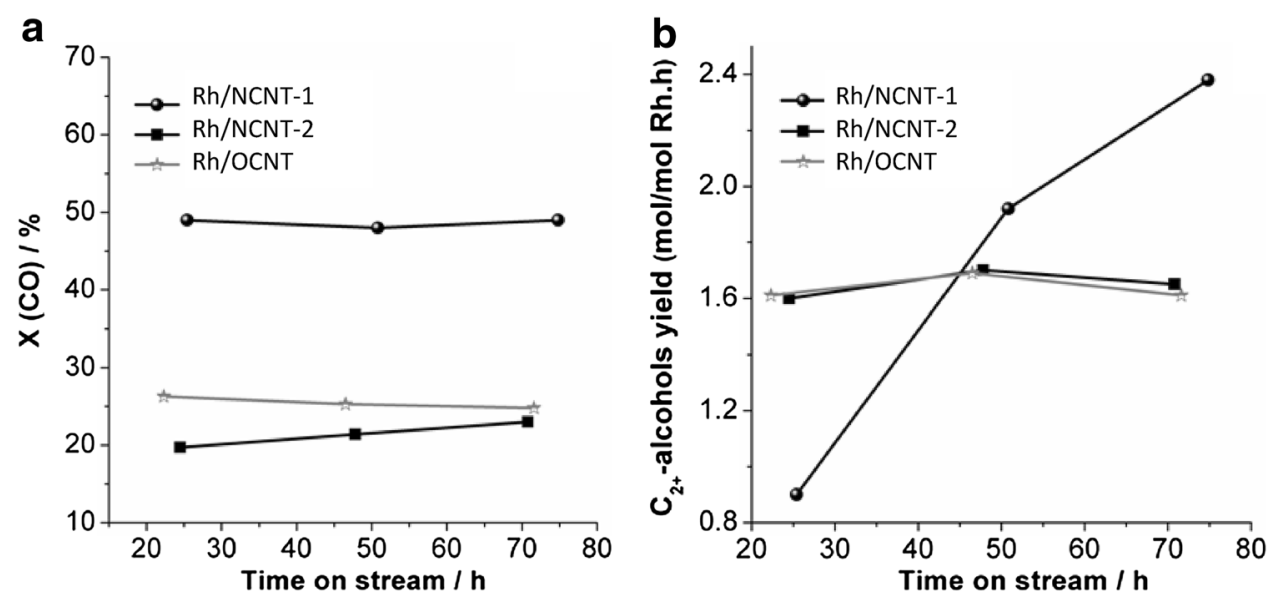
more than twice as much as the conversion on NCNT-2 and OCNT (Table 2). Carbon dioxide is the main product over commercial NCNT-1, whereas $\mathrm{CH}_{4}$ is predominantly formed over NCNT-2 and OCNT, respectively. Perhaps, the residual catalyst impurities in NCNT-1 are not only active in CO hydrogenation to short-chain alkanes, but also show activity in the consecutive water-gas shift reaction.

$\mathrm{Rh} / \mathrm{NCNT}-1, \mathrm{Rh} / \mathrm{NCNT}-2$, and Rh/OCNT show a fairly stable CO conversion within a reaction time of $72 \mathrm{~h}$ (Fig. 3a). However, Rh/NCNT-1 not only outperforms the other catalysts in terms of $\mathrm{CO}$ conversion but also results in the highest yield of $\mathrm{C}_{2+}$ alcohols, by trend even remarkably increasing after $72 \mathrm{~h}$ time on stream (Fig. 2b). This indicates that the catalyst is changing with time on stream.

$\mathrm{Rh} / \mathrm{NCNT}-1$ shows $\mathrm{a} \mathrm{C}_{2+}$ alcohol selectivity of $9.5 \%$ at a $\mathrm{CO}$ conversion of $48.9 \%$, which corresponds to a formation rate of $2.4 \mathrm{~mol} \mathrm{~mol}_{\mathrm{Rh}}{ }^{-1} \mathrm{~h}^{-1}$ (Table 2). Notably, this catalyst provides also the highest formation rate of $\mathrm{CH}_{4}$, whereas $\mathrm{Rh} / \mathrm{NCNT}-2$ and $\mathrm{Rh} / \mathrm{OCNT}$ show increased selectivity to $\mathrm{CH}_{3} \mathrm{OH}, \mathrm{C}_{2+}$ oxygenates, and $\mathrm{CO}_{2}$. However, regarding the chain length distribution of alcohols formed (Figure S6), $\mathrm{Rh} / \mathrm{NCNT}-1$ produces predominantly $\mathrm{C}_{2} \mathrm{H}_{5} \mathrm{OH}$, whereas the spectrum is significantly shifted to $\mathrm{C}_{3+}$ alcohols over $\mathrm{Rh} /$ OCNT.

Although all catalysts appeared stable in terms of $\mathrm{CO}$ conversion over a reaction time of $72 \mathrm{~h}$, a significant sintering of Rh nanoparticles was observed (Fig. 4) compared to the dispersion in the fresh catalysts after reduction (Fig. 1). The enhanced sintering of Rh particles can be partially related to the loss of $\mathrm{N}$ functional groups during the catalytic reaction, as confirmed by elemental analysis (Table $\mathrm{S} 1$ ). The partial loss of $\mathrm{N}$ functionalities likely occurs via Rh-catalyzed hydrogenation under $\mathrm{CO}$ hydrogenation reaction conditions. Similarly, the TPR profiles showed a broad $\mathrm{H}_{2}$ consumption peak starting at $350^{\circ} \mathrm{C}$, which was referred to the reduction of surface $\mathrm{N}$ and $\mathrm{O}$ functionalities. Also the formation of volatile $\mathrm{Rh}$ carbonyl clusters can play a role in the sintering process, which, however, is not detrimental for the net reactivity of the catalyst.

The increase in $\mathrm{C}_{2+}$ oxygenate productivity with time on stream over Rh/NCNT-1 can be explained by modification of the active component $\mathrm{Rh}$ with impurities originating from the support. Notably, Rh-Co alloy formation is identified in used Rh/NCNT-1 (Fig. 5) with Co originating apparently from the catalyst used for synthesis of the NCNT-1 support. Mass transfer most likely occurs via volatile carbonyl clusters. The final Co concentration in the alloy is approx. $30 \%$. The ongoing increase in $\mathrm{C}_{2+}$ alcohols productivity even after $72 \mathrm{~h}$ on stream (Fig. 3b) indicates that this process is still not equilibrated. Other residual elements such as $\mathrm{Mn}$ and $\mathrm{Mg}$ remain in the support, but may also influence the catalytic properties.

The positive impact of transition metal doping on $\mathrm{Rh}$ based catalysts for $\mathrm{C}_{2} \mathrm{H}_{5} \mathrm{OH}$ selectivity and higher alcohols has been numerously reported, for example $[8,32-35]$. As discussed above even low amounts of metal impurities used for the CVD growth of CNTs are unavoidable, in spite of post-purification by acid or base treatment. Considering the abundance of residual Mn and Co species in NCNT-1, a positive impact on both activity and product spectrum is likely. For reference, we prepared Co and Mn doped Rh/OCNT catalysts to get insight into the mode of action of these additives. $\mathrm{RhCo} / \mathrm{OCNT}$ and $\mathrm{RhMn} / \mathrm{OCNT}$ were synthesized via a sequential impregnation method. Both samples provide highly dispersed and homogeneously distributed nanoparticles (Figure S7), similar to that of Rh/OCNT. The Co and Mn modified samples are similarly stable with time-on-stream. The corresponding reactivity patterns after a reaction time of $72 \mathrm{~h}$ are listed in Table 2. Considering the reduced $\mathrm{Rh}$ content (nominally $2 \mathrm{wt} \%$ as compared to $3 \mathrm{wt} \%$ in $\mathrm{Rh} /$ OCNT), a certain increase in activity is observed for the Mn doped catalyst, whereas the selectivity is only weakly shifted to $\mathrm{C}_{2+}$ alcohols/oxygenates. In total, Mn doping results in an increase of $\mathrm{C}_{2+}$ alcohol productivity from 1.6 to
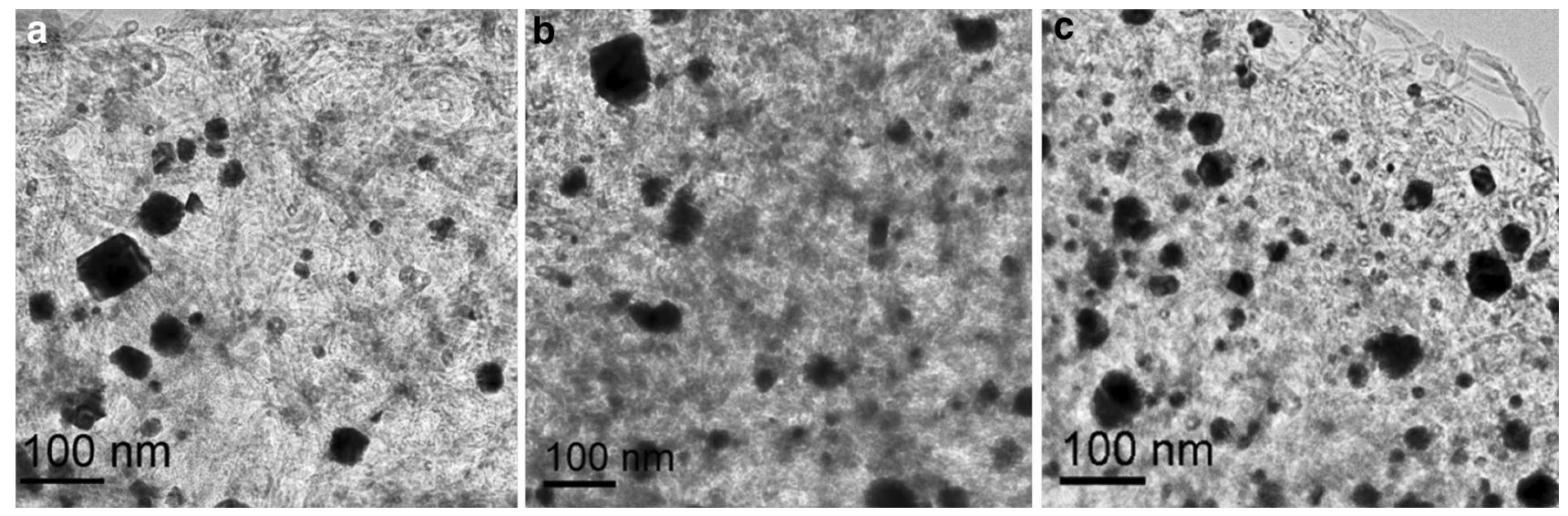

Fig. 4 TEM images of Rh/NCNT-1 (a), Rh/NCNT-2 (b), and Rh/OCNT (c) after reaction 
Fig. 5 HAADF-TEM images of an extra-large particle in used $\mathrm{Rh} / \mathrm{NCNT}-1$ and EDX analysis of used Rh/NCNT-1. Occurrence of $\mathrm{Cu}$ is due to the TEM grid
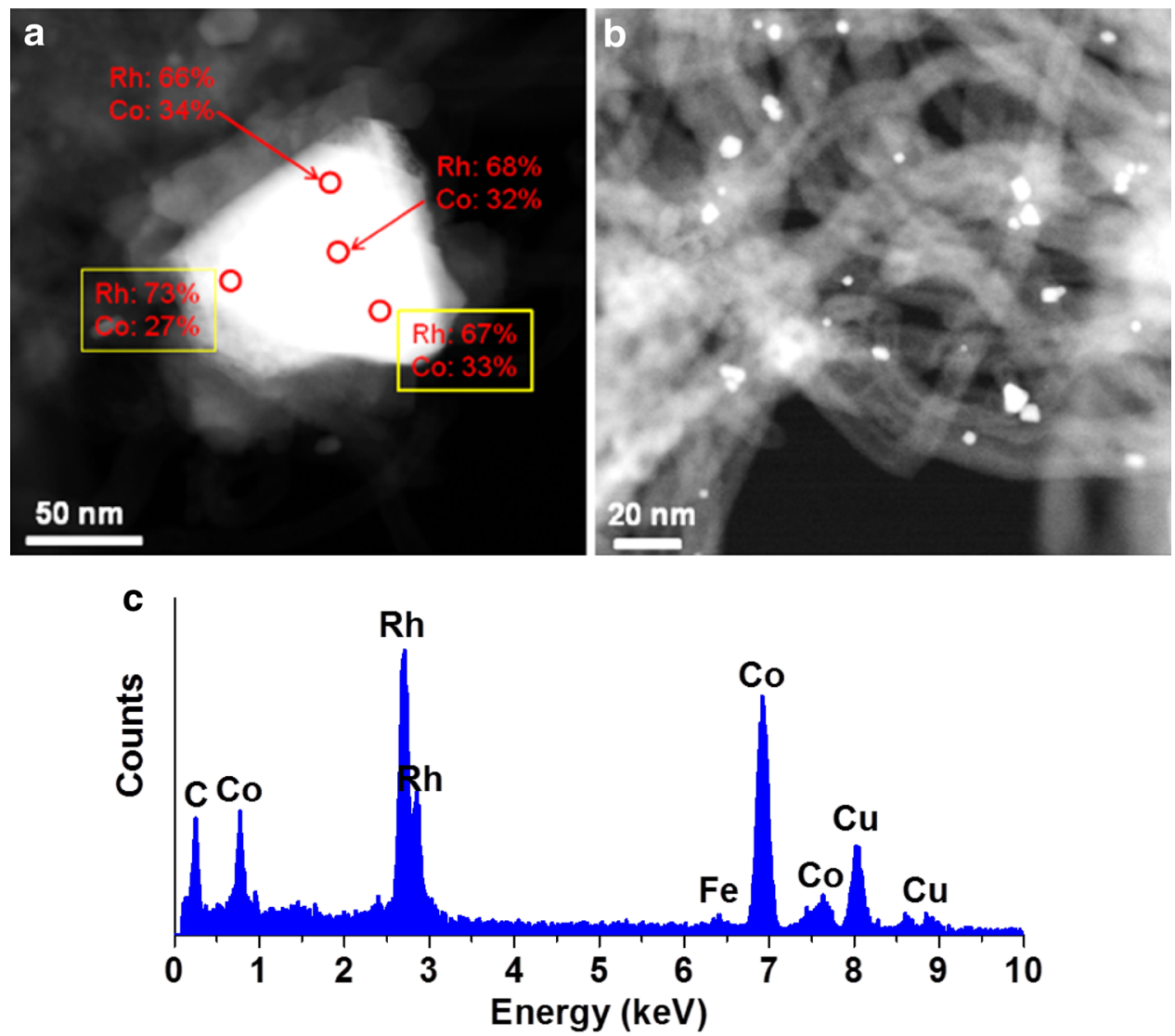

$3.3 \mathrm{~mol} \mathrm{~mol}_{\mathrm{Rh}}{ }^{-1} \mathrm{~h}^{1}$, in agreement with literature reports [8, 32, 33]. Instead, RhCo/OCNT shows a significantly higher $\mathrm{CO}$ conversion of $53 \%$, however, a reduced selectivity to oxygenates. The total productivity of $\mathrm{C}_{2+}$ alcohols remains stable at $1.6 \mathrm{~mol} \mathrm{~mol}_{\mathrm{Rh}}{ }^{-1} \mathrm{~h}^{-1}$. Instead, the product spectrum is dominated by $\mathrm{CH}_{4}$ and lower alkanes, in agreement with the finding that Co promotes the dissociation of $\mathrm{CO}$ to greatly increase the activity and enhance the selectivity to higher alkanes [34-37].

Notably, earlier reports revealed that CNT or metal oxide supported non-promoted $\mathrm{Rh}$ catalysts provide a poor activity to higher alcohols $\left(\mathrm{C}_{3+}\right)[4,8,13]$. Considering the high purity of OCNT and NCNT-2 in our study in terms of residual metal, the significant formation of higher alcohols over both $\mathrm{Rh} / \mathrm{OCNT}$ and $\mathrm{Rh} / \mathrm{NCNT}-2$ might be related to the high pressure applied in our tests, which shifts the equilibrium of alcohol formation via $\mathrm{CO}$ hydrogenation to the product side [3].

\section{Summary}

Supporting $\mathrm{Rh}$ nanoparticles on commercial $\mathrm{N}$-doped CNTs containing residual $\mathrm{Co}$ and $\mathrm{Mn}$ from the CVD growth process results in an active and selective catalyst for the synthesis of higher alcohols. The catalysts are highly stable with time-on-stream although significant sintering of nanoparticles is observed. A dedicated assembly of surface $\mathrm{N}$ functionalities efficiently stabilizes the active phase to form homogeneously distributed and finely dispersed $\mathrm{Rh}$ nanoparticles in the fresh catalyst. A direct influence of the electronic structure of N-doped CNTs on the catalytic action of $\mathrm{Rh}$ active sites is likely, however, could not be proven in this study. Loss of nitrogen is observed under the applied reaction conditions.

Instead, residual Co and $\mathrm{Mn}$ present as impurities in the support efficiently promote the catalyst and results in both increased activity and selectivity to $\mathrm{C}_{2+}$ alcohols by modification of the active $\mathrm{Rh}$ component under reaction conditions of $\mathrm{CO}$ hydrogenation. It is assumed that the formation of Rh-Co alloy is the key factor for enhanced activity, whereas the interaction with Mn species results in an enhanced selectivity to oxygenates. This report exemplifies the resource efficient use of a commercial nanocarbon for synthesis of promoted $\mathrm{Rh}$ catalysts avoiding additional purification and impregnation steps.

Acknowledgments Open access funding provided by Max Planck Society. The author thank G. Weinberg, F. Girgsdies, M. Hashagen, A. Klein-Hoffmann G. Wowsnick, and K. Friedel for experimental assistance. Financial support by the Federal Ministry of Education and Research (BMBF) within the CarboKat project (FKZ 03X0204C) of the Inno. CNT alliance is gratefully acknowledged. 
Open Access This article is distributed under the terms of the Creative Commons Attribution 4.0 International License (http://creativecommons.org/licenses/by/4.0/), which permits unrestricted use, distribution, and reproduction in any medium, provided you give appropriate credit to the original author(s) and the source, provide a link to the Creative Commons license, and indicate if changes were made.

\section{References}

1. Xiao K, Qi XZ, Bao ZH, Wang XX, Zhong LS, Fang KG, Lin MG, Sun YH (2013) Catal Sci Technol 3:1591-1602

2. Lu Y, Cao B, Yu F, Liu J, Bao Z, Gao J (2014) ChemCatChem $6: 473-478$

3. Spivey JJ, Egbebi A (2007) Chem Soc Rev 36:1514-1528

4. Haider MA, Gogate MR, Davis RJ (2009) J Catal 261:9-16

5. Yu J, Mao DS, Han LP, Guo QS, Lu GZ (2013) J Mol Catal A 367:38-45

6. Chuang SSC, Stevens RW, Khatri R (2005) Top Catal 32:225-232

7. Galvis HMT, de Jong KP (2013) ACS Catal 3:2130-2149

8. Pan XL, Fan ZL, Chen W, Ding YJ, Luo HY, Bao XH (2007) Nat Mater 6:507-511

9. Gao J, Mo XH, Goodwin JG (2011) Catal Today 160:44-49

10. Chai SH, Howe JY, Wang XQ, Kidder M, Schwartz V, Golden ML, Overbury SH, Dai S, Jiang DE (2012) Carbon 50:1574-1582

11. Wang HY, Liu JP, Fu JK, Wan HL, Tsai KR (1992) Catal Lett 12:87-96

12. Vannice MA, Ollis DF (1982) J Catal 78:266-266

13. Mavrikakis M, Baumer M, Freund HJ, Norskov JK (2002) Catal Lett 81:153-156

14. Yan Z, Bukur DB, Goodman DW (2011) Catal Today 160:39-43

15. Wijayapala R, Yu F, Jr CUP, Mlsna TE (2014) Appl Catal A 480:93-99

16. Johnson GR, Bell AT (2016) ACS Catal 6:100-114

17. Lu JZ, Yang LJ, Xu BL, Wu Q, Zhang D, Yuan SJ, Zhai Y, Wang XZ, Fan YN, Hu Z (2014) ACS Catal 4:613-621

18. Kang JC, Zhang SL, Zhang QH, Wang Y (2009) Angew Chem 48:2565-2568
19. Schulte HJ, Graf B, Xia W, Muhler M (2012) ChemCatChem 4:350-355

20. Becker MJ, Xia W, Tessonnier JP, Blume R, Yao LD, Schlögl R, Muhler M (2011) Carbon 49:5253-5264

21. Ojeda M, Rojas S, Garcia-Garcia FJ, Granados ML, Terreros P, Fierro JLG (2004) Catal Commun 5:703-707

22. Zhou ST, Zhao H, Ma D, Miao SJ, Cheng MJ, Bao XH (2005) Z Phys Chem 219:949-961

23. Villa A, Wang D, Spontoni P, Arrigo R, Su DS, Prati L (2010) Catal Today 157:89-93

24. Arrigo R, Schuster ME, Wrabetz S, Girgsdies F, Tessonnier JP, Centi G, Perathoner S, Su DS, Schlögl R (2012) ChemSusChem 5:577-586

25. Lv RT, Cui TX, Jun MS, Zhang Q, Cao AY, Su DS, Zhang ZJ, Yoon SH, Miyawaki J, Mochida I, Kang FY (2011) Adv Funct Mater 21:999-1006

26. Wolf A, Michele V, Mleczko L, Assmann J, Buchholz S (2010) US Patent 20100276644

27. Arrigo R, Hävecker M, Wrabetz S, Raoul B, Lerch M, McGregor J, Parrott EPJ, Zeitler JA, Gladden LF, Knop-Gericke A, Schlögl R, Su DS (2010) J Am Chem Soc 132:9616-9630

28. Frank B, Xie Z-L, Trunschke A (2013) Chemie Ingenieur Technik $85: 1290-1293$

29. Jansen RJJ, Vanbekkum H (1995) Carbon 33:1021-1027

30. Chambrion P, Suzuki T, Zhang ZG, Kyotani T, Tomita A (1997) Energy Fuel 11:681-685

31. Tomita A, Tamai Y (1972) J Catal 27:293-300

32. Wilson TP, Kasai PH, Ellgen PC (1981) J Catal 69:193-201

33. Liu J, Tao R, Guo Z, Regalbuto JR, Marshall CL, Klie RF, Miller JT, Meyer RJ (2013) ChemCatChem 5:3665-3672

34. Kusama H, Okabe K, Sayama K, Arakawa H (2000) Appl Organomet Chem 14:836-840

35. Kiviaho J, Reinikainen $M$, Niemelä $M K$, Kataja K, Jääskeläinen S (1996) J Mol Catal A 106:187-195

36. Iglesia E (1997) Appl Catal A 161:59-78

37. Khodakov AY, Chu W, Fongarland P (2007) Chem Rev 107:1692-1744 